\title{
THE CONSTRUCT VALIDITY OF SCORES ON THE WAYS OF COPING QUESTIONNAIRE: CONFIRMATORY ANALYSIS OF ALTERNATIVE FACTOR STRUCTURES
}

\author{
JEFFREY R. EDWARDS AND REGINA M. O'NEILL \\ University of Michigan
}

\begin{abstract}
One of the most widely used measures of coping is the Ways of Coping Questionnaire (WCQ). Despite its widespread use, evidence regarding the construct validity of WCQ scores is limited and inconclusive, due primarily to the use of exploratory factor analyses to examine WCQ data and the absence of evidence regarding the correspondence between the WCQ and coping dimensions specified a priori by Lazarus's transactional theory. The present study uses confirmatory factor analysis to evaluate alternative factor structures for the WCQ, based on previous exploratory factor analyses and a priori coping dimensions derived from Lazarus's theory. Results provide little support for the factor structures examined.
\end{abstract}

In recent years, a growing body of research has examined how individuals cope with stress (Coyne \& Downey, 1991; Dewe, Cox, \& Ferguson, 1993; Edwards, 1988; Monat \& Lazarus, 1991). This research has generated numerous measures of coping (Cohen, 1987; Endler \& Parker, 1990; Latack \& Havlovic, 1992). Of these measures, the most widely used is the Ways of Coping Questionnaire (WCQ) (Folkman \& Lazarus, 1988), a 67-item instrument based on Lazarus's transactional theory of stress (Lazarus \& Folkman, 1984; Lazarus \& Launier, 1978).

Despite the widespread use of the WCQ, evidence regarding the construct validity of WCQ scores is inconclusive. Existing evidence is based primarily on exploratory factor analyses, supplemented by reliability estimates and item-total correlations for subscales based on the resulting factors (e.g.,

Correspondence concerning this article should be addressed to Jeffrey R. Edwards, who is now at the Kenan-Flagler Business School, University of North Carolina, Chapel Hill, NC 27599; e-mail: jredwards@unc.edu.

Educational and Psychological Measurement, Vol. 58 No. 6, December 1998 955-983

(c) 1998 Sage Publications, Inc. 
Aldwin \& Revenson, 1987; Atkinson \& Violato, 1993; Folkman \& Lazarus, 1985; Folkman, Lazarus, Dunkel-Schetter, DeLongis, \& Gruen, 1986; Mishel \& Sorenson, 1993; Smyth \& Williams, 1991). Although informative, this evidence has two major limitations. First, exploratory factor structures for the WCQ have varied considerably, and few of these structures have been cross-validated (Parker, Endler, \& Bagby, 1993). Therefore, these structures might represent artifacts of the samples and procedures used. Moreover, it is unclear which factor structure is appropriate for scoring the WCQ. Some researchers suggest that users of the WCQ should conduct their own factor analyses and develop their own scales (Parker et al., 1993; Tennen \& Herzberger, 1985), but doing so would capitalize on chance sample variation (Campbell, 1976) and inhibit the accumulation of knowledge regarding a consistent set of coping dimensions.

Second, previous studies have not rigorously examined whether the WCQ adequately represents coping dimensions specified a priori by Lazarus's theory. Although general coping dimensions based on the theory have been used to group factors extracted from the WCQ (Aldwin \& Revenson, 1987; Folkman \& Lazarus, 1985; Folkman et al., 1986), numerous specific coping dimensions from the theory are not evident in the WCQ factors. The limited overlap between Lazarus's theory and the WCQ factors is symptomatic of inductive empirical procedures that cannot directly map WCQ items onto specific a priori coping dimensions. This mapping requires a deductive approach in which operational definitions of coping dimensions from Lazarus's theory are used to group WCQ items with similar content, yielding a measurement model that can be tested using confirmatory procedures (Bollen, 1989b; Long, 1983). Until Lazarus's coping dimensions are systematically linked to the WCQ factors, important coping processes might go untested, and the relevance of findings from the WCQ to Lazarus's theory cannot be established.

The purposes of the present study were twofold. The first was to present confirmatory analyses of factor structures derived empirically from the WCQ (Aldwin \& Revenson, 1987; Atkinson \& Violato, 1993; Folkman \& Lazarus, 1985; Folkman et al., 1986; Mishel \& Sorenson, 1993; Parker et al., 1993; Smyth \& Williams, 1991). It was hoped that these analyses would help clarify which of these structures would be more likely to represent stable aspects of the WCQ as opposed to sampling variability or other methodological artifacts. The second purpose of the present study was to test a priori measurement models based on Lazarus's conceptualization of coping (e.g., Lazarus \& Folkman, 1984; Lazarus \& Launier, 1978) in hopes of determining whether items from the WCQ adequately capture the full range of coping strategies described by Lazarus's theory. Taken together, these analyses will provide essential information regarding the construct validity of WCQ scores, both in terms of inherent psychometric properties and the correspondence of WCQ items to the conceptual coping dimensions the WCQ is intended to represent. 


\section{Lazarus's Conceptualization of Coping}

To evaluate the construct validity of scores on the WCQ, we first must consider the conceptualization of coping underlying the WCQ. As noted previously, the WCQ is based on Lazarus's transactional theory of stress and coping (Lazarus \& Folkman, 1984; Lazarus \& Launier, 1978). This theory defines stress as "a particular relationship between the person and the environment that is appraised by the person as taxing or exceeding his or her resources and endangering his or her well-being" (Lazarus \& Folkman, 1984, p. 19). Coping is defined as "constantly changing cognitive and behavioral efforts to manage specific external and/or internal demands that are appraised as taxing or exceeding the resources of the person" (p. 141). Managing demands may include attempts to master the environment or to minimize, avoid, tolerate, or accept stressful conditions.

Successive presentations of the transactional theory have proposed various dimensionalizations of coping. Lazarus (1966) described two broad coping dimensions: (a) defensive reappraisals (e.g., rationalization, denial, isolation), (b) direct action, which comprised strengthening one's resistance to harm, attacking those responsible for harm, avoidance, and inaction. Lazarus, Averill, and Opton (1974) distinguished between (a) direct action on the self or environment and (b) intrapsychic process, which included attention deployment (i.e., ignoring harm or focusing on positive events), reappraisal (i.e., reinterpreting the situation in a positive light), and wish-fulfilling fantasy. Later, Lazarus and Launier (1978) proposed four methods of coping: (a) information seeking, (b) direct action, (c) inhibition of action, and (d) intrapsychic modes. Lazarus and Launier noted that these coping methods could be directed toward the person or environment, focus on past harm or future threat, and involve instrumental action (i.e., altering the stressful person-environment relationship) or palliation (i.e., regulating emotional distress).

More recent descriptions of the theory (e.g., Folkman \& Lazarus, 1980, 1988; Lazarus, 1993; Lazarus \& Folkman, 1984) focus on two general coping dimensions. The first, problem-focused coping, represents efforts to manage or alter the troubled person-environment relationship. These efforts include defining the problem; generating, evaluating, and implementing potential solutions; and/or attempting to cognitively reappraise the situation by shifting one's aspiration level, reducing ego involvement, or finding alternative channels of gratification. The second dimension, emotion-focused coping, refers to efforts to regulate emotional distress. These efforts may entail cognitive reappraisal strategies (e.g., minimization, positive comparisons, seeking good in negative events) or strategies that facilitate reappraisal but are not themselves reappraisals (e.g., selective attention, distancing, avoidance, exercise, meditation, alcohol use, venting anger, seeking emotional support). Although most of these strategies are intended to reduce emotional 
distress, Lazarus and Folkman (1984) posited that some forms of emotionfocused coping (e.g., self-blame) are intended to increase distress, arguing that some people must acutely experience distress before they can obtain relief.

A somewhat different framework was described by Folkman and Lazarus (1990; see also Lazarus, 1993), who identified three basic coping dimensions. The first is attention deployment, which represents efforts to direct attention either toward the source of distress (i.e., vigilance) or away from it (i.e., avoidance). The second comprises cognitive activities that alter the subjective meaning or significance of the stressful encounter, such as denial, distancing, and emphasizing positive aspects of the situation. The third dimension encompasses actions that alter the actual terms of the personenvironment relationship, including cognitive problem solving and direct action on the environment or the self. Folkman and Lazarus (1990) described how certain aspects of these dimensions are captured by factors derived empirically from the WCQ, although some factors (e.g., "planful problem solving") were cited as indicators of two or three dimensions.

The conceptualization of coping developed by Lazarus and his colleagues has several strengths. First, it focuses on actual coping processes rather than on coping resources or styles, which often are poor predictors of coping in specific situations (Carver \& Scheier, 1994; Cohen \& Lazarus, 1973). Second, it distinguishes coping from successful adaptation (e.g., Haan, 1977; Valliant, 1977) by focusing on coping efforts themselves, regardless of their eventual effects. Third, Lazarus's conceptualization views coping as dynamic, changing as a stressful encounter unfolds. By contrast, theories that favor a dispositional approach to understanding coping (e.g., Kobasa, 1979; Lefcourt \& Davidson-Katz, 1991) imply that coping does not change over time.

Despite these strengths, Lazarus's conceptualization of coping has at least three drawbacks. First, coping dimensions have changed with successive presentations of the theory, with no clear theoretical or empirical rationale for these changes. Although general distinctions between coping strategies directed toward the situation versus the self have been maintained, dimensions within these broad categories have been modified with little indication that prior dimensionalizations were conceptually or empirically inadequate. These modifications make it difficult to determine which dimensions are most central to Lazarus's theory and, hence, which dimensions should be used to evaluate the construct validity of scores on measures based on the theory.

A second weakness of Lazarus's theory is that the proposed coping dimensions do not clearly correspond to the stated definition of coping, which focuses on attempts to manage internal or external demands that tax or exceed personal resources. Based on this definition, coping should serve two basic functions: managing or reducing demands and enhancing personal resources to meet demands. Although the general coping dimensions described by Lazarus involve the situation and self, they do not explicitly entail efforts 
to alter situational demands and personal resources. More specific coping dimensions proposed by Lazarus describe how people cope in particular situations, but it is unclear whether or how these dimensions correspond to managing demands or enhancing personal resources.

A final drawback of Lazarus's theory is that the conceptual distinctions among coping dimensions often are unclear. For example, Lazarus and Folkman (1984) noted that "certain forms of emotion-focused coping are reappraisals, other forms are not, and still others sometimes are and sometimes are not" (p. 151). Moreover, some forms of problem-focused reappraisal (e.g., reducing ego involvement) resemble emotion-focused reappraisal (e.g., minimization). In defense of the overlap among coping dimensions, Lazarus and Folkman (1984) argued that one form of coping may serve multiple functions, as when a student takes a tranquilizer to reduce emotional distress (i.e., emotion-focused coping) and thereby enhance exam performance (i.e., problem-focused coping). However, this example does not show that taking a tranquilizer represents both emotion- and problem-focused coping; rather, it suggests a causal sequence in which taking a tranquilizer reduces emotional distress, which then facilitates exam performance. Based on this sequence, taking a tranquilizer should be viewed as emotion-focused coping because it directly affects emotional distress and only indirectly affects the situation (i.e., exam performance). Conceptual distinctions such as these among coping dimensions are critical to developing coping measures whose scores achieve discriminant validity and permit meaningful examination of causal relationships among coping processes.

\section{Development of the Ways of Coping Questionnaire}

The first version of the WCQ, the Ways of Coping Checklist (WCC) (Folkman \& Lazarus, 1980), consisted of 68 binary (i.e., yes/no) items derived from Lazarus's theory and previous coping research (e.g., Mechanic, 1962; Sidle, Moos, Adams, \& Cady, 1969). According to Folkman and Lazarus (1980), the WCC items represented "defensive coping (e.g., avoidance, intellectualization, isolation, suppression), information seeking, problem solving, palliation, inhibition of action, direct action, and magical thinking" (p. 224). A similar description of the WCC was provided by Folkman and Lazarus (1988), although palliation and magical thinking were subsumed in the defensive coping dimension. Lazarus and Folkman (1984) presented a somewhat different account, indicating that the WCC items represented problem- and emotion-focused coping as well as "direct action, inhibition of action, information search, and a complex category referred to as intrapsychic or cognitive coping" (p. 318), corresponding to the four coping dimensions of Lazarus and Launier (1978). Although Lazarus and colleagues have not explicitly resolved the inconsistencies among these descriptions, it appears that magical thinking and defensive coping (Folkman \& Lazarus, 
1980) both represent cognitive coping (Lazarus \& Folkman, 1984) and that palliation (Folkman \& Lazarus, 1980) is equated with emotion-focused coping (Lazarus \& Folkman, 1984).

The first study to examine the psychometric properties of the WCC was conducted by Folkman and Lazarus (1980). Prior to analysis, 10 raters classified the WCC items into problem- or emotion-focused coping categories. A two-factor principal components analysis using data from 100 middle-aged community residents indicated that 21 of the 27 items classified as problem focused correlated more highly with one factor and that 28 of the 41 items classified as emotion focused correlated more highly with the other factor. Reliability estimates (Cronbach's alpha) for subscales based on these factors were .80 and .81 , respectively. Based on rater evaluations and item-total correlations, 1 item was moved from the problem-focused scale to the emotionfocused scale, and 2 items were dropped from each scale, yielding 24 and 40 items, respectively.

Subsequent analyses of the WCC found that the item classification used by Folkman and Lazarus (1980) had collapsed empirically distinct dimensions. For example, Aldwin, Folkman, Schaefer, Coyne, and Lazarus (1980) reanalyzed the Folkman and Lazarus (1980) data and extracted seven factors consisting of one problem-focused coping factor, five emotion-focused coping factors (minimizing threat, wishful thinking, seeking emotional support, blaming oneself, and interpreting opportunities for personal growth), and one mixed factor. By contrast, a separate sample analyzed by Vitaliano, Russo, Carr, Maiuro, and Becker (1985) yielded six factors: problem-focused coping, wishful thinking, seeking social support, blaming oneself/avoidance, minimization, and a weak unnamed factor. A different six-factor solution was extracted in a study by Vingerhoets and Flohr (1984), who labeled the factors problem focused/help seeking, wishful thinking/escape, acceptance, withholding action, self-blame, and growth. Although the factor structures found in these three studies shared certain similarities, only 16 items were associated with factors with analogous labels across all three studies. A markedly different structure was reported by Parkes (1984), who obtained three factors labeled general coping, direct coping, and suppression. However, unlike the preceding studies, Parkes retained a solution in which numerous items had substantial associations with multiple factors, which may partly account for the smaller number of factors obtained. Across all four studies, reliability estimates for scores on factor-based subscales averaged .77 and ranged from .56 to .91 .

Folkman and Lazarus (1985) developed the WCQ from the WCC by deleting or rewording items that were redundant or unclear, adding items suggested by respondents, and changing the binary response format to a 4-point Likert-type scale ranging from does not apply and/or not used to used a great deal. A factor analysis yielded six factors, but one factor contained items describing three distinct emotion-focused strategies, which Folkman and 
Lazarus (1985) separated into three factors. The result was eight factors labeled problem-focused coping, wishful thinking, distancing, emphasizing the positive, tension reduction, self-blame, self-isolation, and seeking social support. Folkman et al. (1986) extracted a different set of eight factors labeled planful problem solving, confrontive coping, accepting responsibility, escape avoidance, distancing, self-control, positive reappraisal, and seeking social support. Aldwin and Revenson (1987) also reported eight factors comprising instrumental action, negotiation, escapism, cautiousness, minimization, self-blame, seeking meaning, and support mobilization. Despite the apparent similarities among these results, only 18 items were associated with conceptually similar factors across all three studies.

Several additional factor analyses of the WCQ have been reported recently. Smyth and Williams (1991) found eight factors described as focusing, problem solving/distancing, wishful thinking, acceptance/optimism, withdrawal/risk taking, positive reappraisal, substitution, and seeking social support. A different eight-factor solution was reported by Atkinson and Violato (1993), who extracted factors representing problem-focused coping, accepting responsibility, confrontive coping, emotional distancing, positive reappraisal, seeking social support, cognitive escape/avoidance, and physiological escape/avoidance. Mishel and Sorenson (1993) forced a twofactor solution to separate items into problem- and emotion-focused coping categories and then factored these items separately. The 38 problem-focused items yielded four factors (bargaining, focus on the positive, seeking social support, and concentrated efforts), whereas the 27 emotion-focused items yielded three factors (wishful thinking, detachment, and acceptance). Finally, Parker et al. (1993) extracted four factors representing problemfocused coping, confrontation/seeking social support, distancing/avoidance, and denial. The smaller number of factors found by Parker et al. might have been partly due to their factor retention criteria, which included the stability of the factor solution across samples and, hence, might have favored simpler factor structures. Across all seven analyses of the WCQ, 32 items were associated with conceptually similar factors in a simple majority (i.e., at least four) of the analyses, whereas only 5 items were associated with similar factors in all seven analyses. Reliability estimates from studies in which they were reported (Aldwin \& Revenson, 1987; Folkman \& Lazarus, 1985; Folkman et al., 1986; Mishel \& Sorenson, 1993) for scores on the factor-based subscales were comparable to those for the WCC, averaging . 73 and ranging from .56 to .85 .

The preceding evidence suggests two general conclusions regarding the construct validity of WCQ scores. First, the correspondence between the factor structure of the WCQ and the coping dimensions specified by Lazarus's theory has not been rigorously evaluated. This omission is due partly to ambiguities in Lazarus's theory regarding the dimensionality of coping, which has been described alternatively as 2 general categories (Folkman \& Lazarus, 
1980), 3 or 4 somewhat more specific categories (Folkman \& Lazarus, 1990; Lazarus et al., 1974; Lazarus \& Launier, 1978), and 20 individual coping strategies (Folkman \& Lazarus, 1984). The lack of evidence regarding the correspondence between the WCQ and Lazarus's theory also is due to the use of exploratory factor analysis to assess the dimensionality of the WCQ. Such analyses are largely data driven and provide only indirect evidence regarding the correspondence between factors and conceptual dimensions specified a priori by theory. More direct evidence may be obtained from confirmatory procedures such as confirmatory factor analysis (Bollen, 1989b; Long, 1983).

A second conclusion is that factor structures for the WCQ have varied considerably across studies. This variability is due partly to differences in the criteria used to determine the number of factors to retain. Some studies have retained factors with eigenvalues greater than 1 (Atkinson \& Violato, 1993; Smyth \& Williams, 1991), others have relied on the stability of factor structures across samples (Parker et al., 1993), and still others have focused on factor interpretability (Aldwin \& Revenson, 1987; Folkman \& Lazarus, 1985). In addition, the assignment of items to factors has been based on different criteria such as factor structure coefficients greater than .30 (Atkinson \& Violato, 1993; Smyth \& Williams, 1991), greater than 35 (Parker et al., 1993), or greater than .40 (Aldwin \& Revenson, 1987); consistency of factor structure coefficients across analyses (Folkman et al., 1986); and item content (Folkman \& Lazarus, 1985). Finally, samples have varied across studies, ranging in size from 149 (Atkinson \& Violato, 1993) to 530 (Parker et al., 1993) and representing different populations such as undergraduate students, cancer patients, and community residents. For these reasons, it is difficult to determine whether any of the factor structures reported in the literature is generalizable beyond the sample and procedure on which it was based.

Two recent studies examined the generalizability of factor structures from the WCQ using confirmatory factor analysis. Edwards and Baglioni (1993) tested the eight-factor structure obtained by Folkman et al. (1986) using data from 116 master of business administration students and obtained a poor fit, as evidenced by a statistically significant chi-square and low fit indexes ranging from .41 for the Tucker-Lewis index (TLI) (Tucker \& Lewis, 1973) to .60 for the goodness-of-fit index (GFI) (Jöreskog \& Sörbom, 1993). Parker et al. (1993) tested orthogonal and oblique confirmatory versions of the six- and eight-factor models found by Folkman and Lazarus (1985) and the eightfactor model found by Folkman et al. (1986), respectively, using data from 530 college students. Each model yielded a statistically significant chisquare, and GFIs and adjusted goodness-of-fit indexes (AGFIs) ranged from .63 to .82 , indicating poor to modest fit. Parker et al. (1993) also tested orthogonal and oblique versions of their own exploratory four-factor model using a separate sample of 392 students and obtained statistically significant chi-squares and modest GFIs and AGFIs, ranging from .73 to .78. 


\section{The Present Study}

The present study extended the work of Edwards and Baglioni (1993) and Parker et al. (1993) in several ways. First, it tested a more comprehensive set of factor structures derived from the WCQ, including those reported by Folkman and Lazarus (1985), Folkman et al. (1986), and Parker et al. (1993) as well as those of Aldwin and Revenson (1987), Atkinson and Violato (1993), Mishel and Sorenson (1993), and Smyth and Williams (1991). Second, the present study employed a broader set of criteria for assessing model fit, drawing from recent work on testing structural equation models (Bentler, 1990; Bollen \& Long, 1993; McDonald \& Marsh, 1990). Criteria used by Parker et al. (1993) have several important weaknesses and no longer are recommended for assessing model fit (Gerbing \& Anderson, 1992). Third, and perhaps most important, the present study tested a set of a priori models based on Lazarus's conceptualization of coping. Although testing models based on exploratory factor analysis provides useful information regarding the factorial stability and inherent psychometric properties of the WCQ, these tests do not evaluate the degree of correspondence between the WCQ and the various coping dimensions encompassed by Lazarus's theory. This evaluation is accomplished instead by testing models constructed a priori according to conceptual criteria, as in the procedure used here.

\section{Method}

\section{Sample}

Copies of the WCQ were mailed to 2,514 graduates of a large graduate business school in the eastern United States. Of the 2,514 potential respondents, 250 were not employed (e.g., between jobs, raising children full-time, attending school full-time) and 105 were returned as undeliverable, leaving a potential sample of 2,159. After two reminders, a total of 783 surveys were returned, yielding a $36 \%$ response rate. Of the 783 returned surveys, 654 yielded complete responses on all WCQ items. This sample size provided from 4.42 to 11.47 cases per parameter for the models estimated and, hence, was considered adequate (Bentler \& Chou, 1987). The final sample was predominantly male $(71 \%)$, averaged 35 years of age (range $=25$ to 55 years), and averaged 3.96 years of work experience with their current employers (range $=0$ to 21 years). Respondents were employed in finance (30\%), marketing (25\%), consulting (17\%), and operations (6\%), with the remaining $22 \%$ distributed among general management, accounting, human resources management, sales management, and other specific job types indicated by the respondents. 


\section{Measures}

Respondents completed the 66-item WCQ (Folkman \& Lazarus, 1988). Following Folkman and Lazarus (1988), instructions asked respondents to answer each item in terms of how they coped with a specific self-named stressful situation. All items were answered using the recommended 4-point response scale ranging from does not applyor not used to used a great deal.

\section{Analysis}

Two sets of confirmatory factor analyses were conducted, both using LISREL 8 (Jöreskog \& Sörbom, 1993) with maximum likelihood estimation. First, factor structures derived from exploratory factor analyses of the WCQ were tested, drawing from studies that used the WCQ intact (Aldwin \& Revenson, 1987; Atkinson \& Violato, 1993; Folkman \& Lazarus, 1985; Folkman et al., 1986; Mishel \& Sorenson, 1993; Parker et al., 1993; Smyth \& Williams, 1991). One exception was Aldwin and Revenson (1987), who split Item 53 ("Accepted it since nothing could be done") into the two statements embedded in the original item. However, the new items ultimately were identified with the same factor, suggesting that this modification had little effect on the obtained factor structure. Following Parker et al. (1993), the six- and eight-factor solutions reported by Folkman and Lazarus (1985) both were tested. In addition, the second-order factor structure implied by Mishel and Sorenson's (1993) procedure was tested along with a first-order, seven-factor model. Finally, a common model was tested that contained the 32 items that were identified with conceptually similar factors in at least four of the seven extant exploratory analyses. All models were specified as oblique, based on the premise that coping strategies such as those associated with the WCQ often are used concurrently (Folkman \& Lazarus, 1980) and prior evidence indicating that factors derived from the WCQ generally are correlated (e.g., Folkman \& Lazarus, 1985; Folkman et al., 1986; Parker et al., 1993).

Second, the correspondence between the WCQ items and the coping dimensions specified by Lazarus's theory was evaluated. This procedure began by constructing operational definitions of coping dimensions described by Lazarus and his colleagues (Folkman, 1982; Folkman \& Lazarus, 1980, 1988, 1990; Lazarus, 1993; Lazarus \& Folkman, 1984; Lazarus \& Launier, 1978). Most definitions were taken verbatim from the original sources, although some required consultation of sources cited by Lazarus (Mechanic, 1962; Sidle et al., 1969; Weisman \& Worden, 1976-1977) or the general psychoanalytic literature (Rychlak, 1981). After combining redundant dimensions, a total of 30 definitions were retained (see appendix). These definitions were provided to 10 judges trained in various areas of social and applied psychology, who rated the degree to which each WCQ item 
represented each coping dimension, using a 7-point scale ranging from -3 (definitely no) to 0 (not sure) to +3 (definitely yes). This procedure was used instead of categorically assigning each item to one dimension so as to identify items that potentially represent multiple dimensions and to determine the degree to which each item represented each dimension in an absolute sense. Interrater agreement for each item was calculated using the intraclass correlation coefficient (ICC), treating judges as a random factor and dimensions as a fixed factor. This form of the ICC is appropriate when mean differences between judges are treated as error, as in the present case (Shrout \& Fleiss, 1979). ICC values averaged .76 across all 66 items and ranged from .44 for Item 60 ("I prayed") to .94 for Item 3 ("Turned to work or substitute activity to take my mind off things").

Item ratings were averaged and used to assign items to coping dimensions described by Lazarus and colleagues. In total, five dimensionalizations were examined: the 1 problem-focused and 3 intrapsychic dimensions described by Lazarus et al. (1974), the 4 general dimensions delineated by Lazarus and Launier (1978), the 8 nonredundant dimensions described by Folkman and Lazarus $(1980,1988)$ as the basis for the WCC, the 8 problem-focused and 12 emotion-focused dimensions identified by Lazarus and Folkman (1984), and the 3 general dimensions proposed by Folkman and Lazarus (1990) and Lazarus (1993) (see Table 1). These dimensionalizations encompass the time frame from the early development of the WCC to the most recent description of Lazarus's theory at the time the study was conducted.

Several procedures were used to assign items to dimensions. Initially, an item was assigned to all dimensions on which it had an average rating of 1 or higher, representing a verbal anchor of maybe so in response to the question of whether the item represented the dimension. Unfortunately, this procedure yielded many dimensions with fewer than two items (i.e., the minimum required for identification in oblique measurement models) (Bollen, 1989b). A less stringent criterion was then used in which items were assigned to dimensions on which their average rating was greater than 0 . Although this increased the number of items per dimension, it resulted in numerous "doublets" (i.e., items salient with 2 or more factors) and yielded factor correlations that often exceeded unity. Doublets were then eliminated by assigning items to the single factor on which they had the highest average rating. Factors with fewer than two items assigned were then eliminated to achieve identification. This procedure permitted tests of all 3 factors described by Folkman and Lazarus (1990), all 4 factors specified by Lazarus et al. (1974) and Lazarus and Launier (1978), 7 of the 8 factors described by Folkman and Lazarus (1980), and 9 of the 20 factors identified by Lazarus and Folkman (1984). The factors tested are indicated in Table 1.

For both sets of analyses, several criteria were used to assess overall model fit. The first was the chi-square test statistic, representing the deviation of the covariance matrix reproduced by the estimated model from the sample 
Table 1

Summary of Conceptually Derived Coping Dimensionalizations Examined

\begin{tabular}{|c|c|}
\hline Source & Dimensions \\
\hline Lazarus et al. (1974) & $\begin{array}{l}\text { Direct action } \\
\text { Attention deployment } \\
\text { Reinterpreting the situation in a positive light (reappraisal) } \\
\text { Wish-fulfilling fantasy }\end{array}$ \\
\hline Lazarus and Launier (1978) & $\begin{array}{l}\text { Information seeking } \\
\text { Direct action } \\
\text { Inhibition of action } \\
\text { Intrapsychic modes }\end{array}$ \\
\hline $\begin{array}{l}\text { Folkman and Lazarus } \\
(1980,1988)\end{array}$ & $\begin{array}{l}\text { Avoidance/suppression } \\
\text { Intellectualization/isolation }^{\mathrm{e}} \\
\text { Information seeking } \\
\text { General problem solving } \\
\text { Palliation } \\
\text { Inhibition of action } \\
\text { Direct action } \\
\text { Magical thinking }\end{array}$ \\
\hline Lazarus and Folkman (1984) & $\begin{array}{l}\text { General problem solving } \\
\text { Defining the problem } \\
\text { Generating potential solutions } \\
\text { Evaluating potential solutions } \\
\text { Implementing potential solutions } \\
\text { Shifting one's aspiration level } \\
\text { Reducing ego involvement } \\
\text { Finding alternative channels of gratification } \\
\text { Avoidance } \\
\text { Minimization } \\
\text { Distancing } \\
\text { Selective attention } \\
\text { Positive comparisons } \\
\text { Seeking positive value from negative events } \\
\text { Self-blame } \\
\text { Exercise } \\
\text { Meditation } \\
\text { Alcohol use } \\
\text { Venting anger } \\
\text { Seeking emotional support }\end{array}$ \\
\hline $\begin{array}{l}\text { Folkman and Lazarus (1990); } \\
\text { Lazarus (1993) }\end{array}$ & $\begin{array}{l}\text { Attention deployment } \\
\text { Changing the subjective meaning or significance of the } \\
\text { person-environment relationship } \\
\text { Changing the actual terms of the person-environment } \\
\text { Relationship }\end{array}$ \\
\hline
\end{tabular}

Note. Dimensions with an adequate number of items to permit testing (i.e., two or more) are italicized. a. Unlike Folkman and Lazarus (1990, p. 319), who define attention deployment as focusing attention toward or away from the source of distress, Lazarus et al. (1974, p. 261) define attention deployment in terms of avoidance and selective attention. Therefore, for the Lazarus et al. (1974) model, attention deployment was operationalized by combining the avoidance and selective attention items.

b. Reinterpreting the situation in a positive light (Lazarus et al., 1974, p. 261) was equated with seeking positive value from negative events (Lazarus \& Folkman, 1984, p. 150) because both represent cognitive actions to find something positive in the situation.

c. Wish-fulfilling fantasy (Lazarus et al., 1974, p. 261) was equated with magical thinking (Folkman \& Lazarus, 1980, p. 224; Mechanic, 1962, p. 136) given that both refer to fictional or illusory thoughts intended to provide emotional relief.

d. Suppression (Folkman \& Lazarus, 1980, p. 224; Weisman \& Worden, 1976-1977, p. 6) was equated with avoidance (Lazarus \& Folkman, 1984, p. 150) because both involve consciously putting thoughts out of one's mind and thinking of other things.

e. Isolation (Folkman \& Lazarus, 1980, p. 224) was equated with intellectualization (Lazarus, 1966, p. 47) in that both refer to separating a cognition from its emotional content. 
covariance matrix. As is widely known, the chi-square statistic is highly sensitive to sample size such that models that fit the data reasonably well often are rejected for moderate to large samples (Bentler \& Bonett, 1980; Gerbing \& Anderson, 1992). Therefore, four additional criteria were examined. One is the root mean squared error of approximation (RMSEA) (Steiger, 1990), which is an estimate of the discrepancy per degree of freedom between the original and reproduced covariance matrices in the population. Browne and Cudeck (1993) suggested that an RMSEA of .05 represents close fit. The remaining three criteria were the TLI (Tucker \& Lewis, 1973), the incremental fit index (IFI) (Bollen, 1989a), and the comparative fit index (CFI) (Bentler, 1990). These indexes represent the relative improvement in fit of the hypothesized model over the null model (in which all observed variables are specified as uncorrelated), have expected values of 1.0 when the hypothesized model is true in the population, and are relatively independent of sample size (Bentler, 1990). Although standards for indexes such as these are difficult to establish (Marsh, Balla, \& McDonald, 1988), a value of .90 or higher has been suggested as indicating adequate fit (Bentler \& Bonett, 1980).

In addition to assessing overall model fit, information regarding the psychometric properties of the factors from each model was examined, focusing on standardized item coefficients, Cronbach's alpha (Cronbach, 1951), and the average variance extracted for each factor (AVE) (Fornell \& Larcker, 1981). For alpha, the .70 criterion suggested by Nunnally (1978) was used as a standard for adequate reliability. AVE represents the amount of variance captured by the factor relative to the variance due to measurement error (Fornell \& Larcker, 1981, p. 45). Fornell and Larcker (1981) suggested that AVE should exceed .50 for a factor to be considered meaningful.

\section{Results}

\section{Item Distributions}

Distributions of the WCQ items were examined for range restriction and multivariate normality. All 66 items yielded responses throughout the full possible range; thus, range restriction was not evident. However, most items showed some skewness, kurtosis, or both. Deviations from multivariate normality were statistically significant for skewness $(Z=149.61, p<.05)$ and kurtosis $(Z=10.27, p<.05)$. Although such deviations do not bias maximum likelihood parameter estimates, they tend to inflate standard errors and chisquare values (Bollen, 1989b; Satorra, 1990). Methods of estimation that do not require multivariate normality are available (Browne, 1984), but these methods demand very large samples (Bollen, 1989b; Jöreskog \& Sörbom, 
1993). Therefore, maximum likelihood estimation was used in the present study, acknowledging its drawbacks for data that are not multivariate normal.

\section{Confirmatory Tests of Exploratory Factor Models}

Table 2 summarizes results from confirmatory factor analyses of the 10 models derived from exploratory factor analyses of the WCQ. For each model, the chi-square was statistically significant and the RMSEA was significantly greater than the .05 criterion. Moreover, TLI, IFI, and CFI were well below the .90 criterion for all models, indicating less than adequate fit. Of the nine original models, the Smyth and Williams (1991) model and the Mishel and Sorenson (1993) second-order model yielded the worst fit, with all three fit indexes falling below .60, whereas the eight-factor Folkman and Lazarus (1985) model yielded the best fit, with fit indexes above .70. The common model yielded the best overall fit, with fit indexes ranging between .75 and .79, although the fit of this model was only modest in an absolute sense. Finally, several factors failed to achieve discriminant validity (i.e., exhibited correlations with other factors that did not differ significantly from unity) including the acceptance, bargaining, concentrated efforts, and detachment factors from the Mishel and Sorenson (1993) model and the focusing, planful problem-solving/distancing, acceptance/optimism, withdrawal/risk-taking, and substitution factors from the Smyth and Williams (1991) model.

Across all models, reliabilities for scores on factor-based subscales averaged .65 and ranged from .39 to .79 , notably less than the average of .73 and the range of .56 to .85 found previously for the WCQ. Reliabilities were highest for scores based on the Parker et al. (1993) model, due partly to the larger number of items assigned to each factor. Reliabilities were lowest for the common model, which, by construction, had the fewest items. Overall, the proportion of reliability estimates that exceeded .70 was $38 \%$, meaning that scores from most subscales did not achieve conventional standards for reliability (Nunnally, 1978).

Standardized coefficients linking items to factors were modest in size, averaging . 49 across all models. The common model yielded the highest values, averaging .55 and ranging from .27 to .83 , whereas the Smyth and Williams (1991) model yielded the lowest values, averaging .43 and ranging from .15 to .76 . AVE values also were low, averaging .26 and ranging from .13 to .38 , with none reaching the .50 criterion (Fornell \& Larcker, 1981). The highest AVE values again were found for the common model, followed closely by the Aldwin and Revenson (1987) model, whereas the lowest values were for the Smyth and Williams (1991) model.

To illustrate the sources of poor fit for the preceding models, Table 3 reports supplemental results for the Folkman et al. (1986) model. This model 


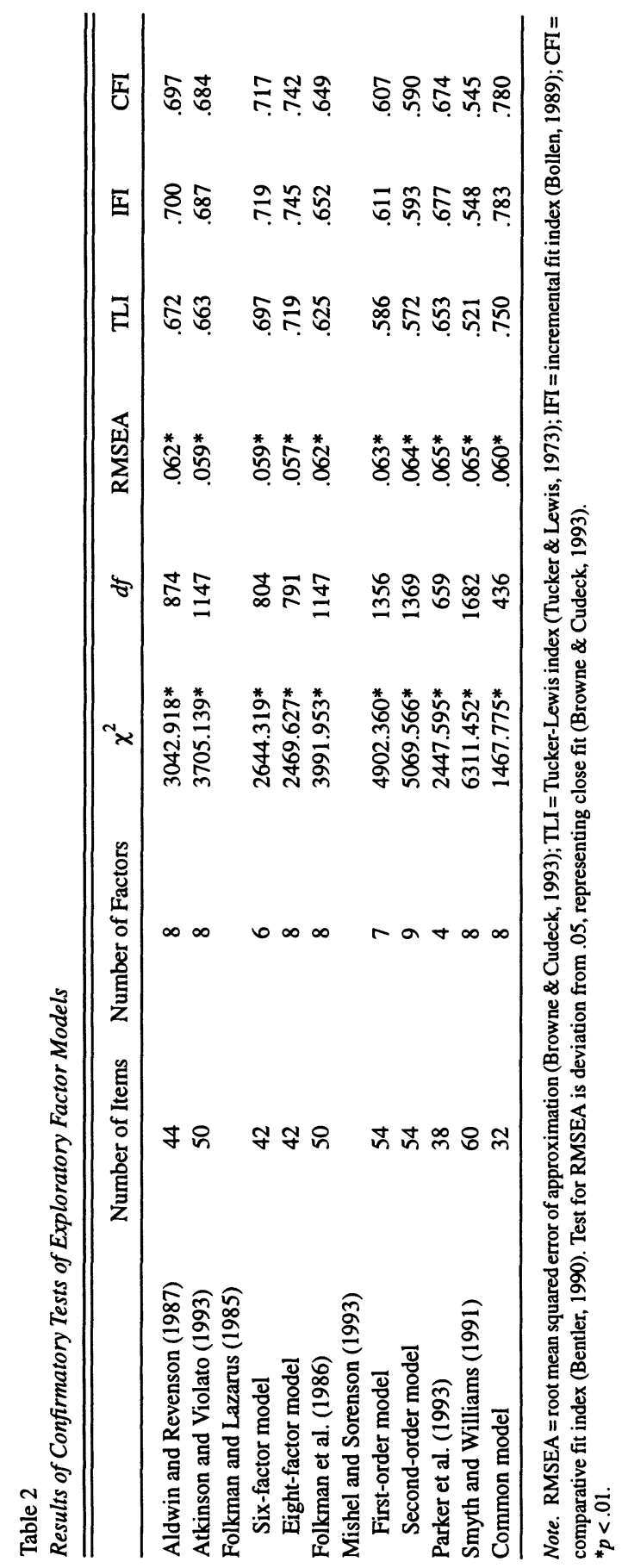


was chosen because it currently serves as the basis for scoring the WCQ (Folkman \& Lazarus, 1988) and, hence, merits close scrutiny. Of the 50 items in the model, 38 yielded significant modification indexes for coefficients on factors other than the intended factor, and for 3 of these items (Items 6, 15, and 20), the expected coefficient on an alternative factor was larger in absolute magnitude than the coefficient on the intended factor. In addition, 11 other items (Items 14, 21, 23, 30, 34, 38, 39, 43, 45, 62, and 63) yielded significant modification indexes on four or more alternative factors. Most of these items are phrased in general terms, which increases the likelihood of obtaining modest coefficients on multiple factors.

Some items had fairly high coefficients on the intended factor but differed in content from other items assigned to the same factor. For example, Items 40 ("Avoided being with people in general") and 47 ("Took it out on other people") had fairly high coefficients on the escape/avoidance factor but represent distinct and somewhat inconsistent coping strategies. Similarly, Items 18 ("Accepted sympathy and understanding from someone") and 31 ("Talked to someone who could do something concrete about the problem") on the seeking social support factor both refer to interaction with another person, but the nature of that interaction is fundamentally different. Hence, these two items might not reflect the same factor; rather, they might represent correlated but conceptually distinct factors.

\section{Confirmatory Tests of Conceptually \\ Based Coping Dimensionalizations}

Table 4 reports results from confirmatory factor analyses of the five models based on conceptual discussions of the coping dimensions underlying Lazarus's theory. Each model produced a statistically significant chi-square and an RMSEA that was significantly greater than the .05 criterion $(p<.05)$. All TLI, IFI, and CFI values were below the .90 minimum criterion, with the smallest values obtained for the Lazarus and Launier (1978) model and the largest for the Lazarus and Folkman (1984) model. All models except that based on Folkman and Lazarus (1990) yielded factors that did not achieve discriminant validity, including the attention deployment and wish-fulfilling fantasy factors from the Lazarus et al. (1974) model; the information-seeking and direct action factors from the Lazarus and Launier (1978) model; the general problem-solving, palliation, and direct action factors from the Folkman and Lazarus (1980) model; and the general problem-solving, defining the problem, evaluating potential solutions, avoidance, minimization, distancing, and seeking positive value from negative events factors from the Lazarus and Folkman (1984) model. 


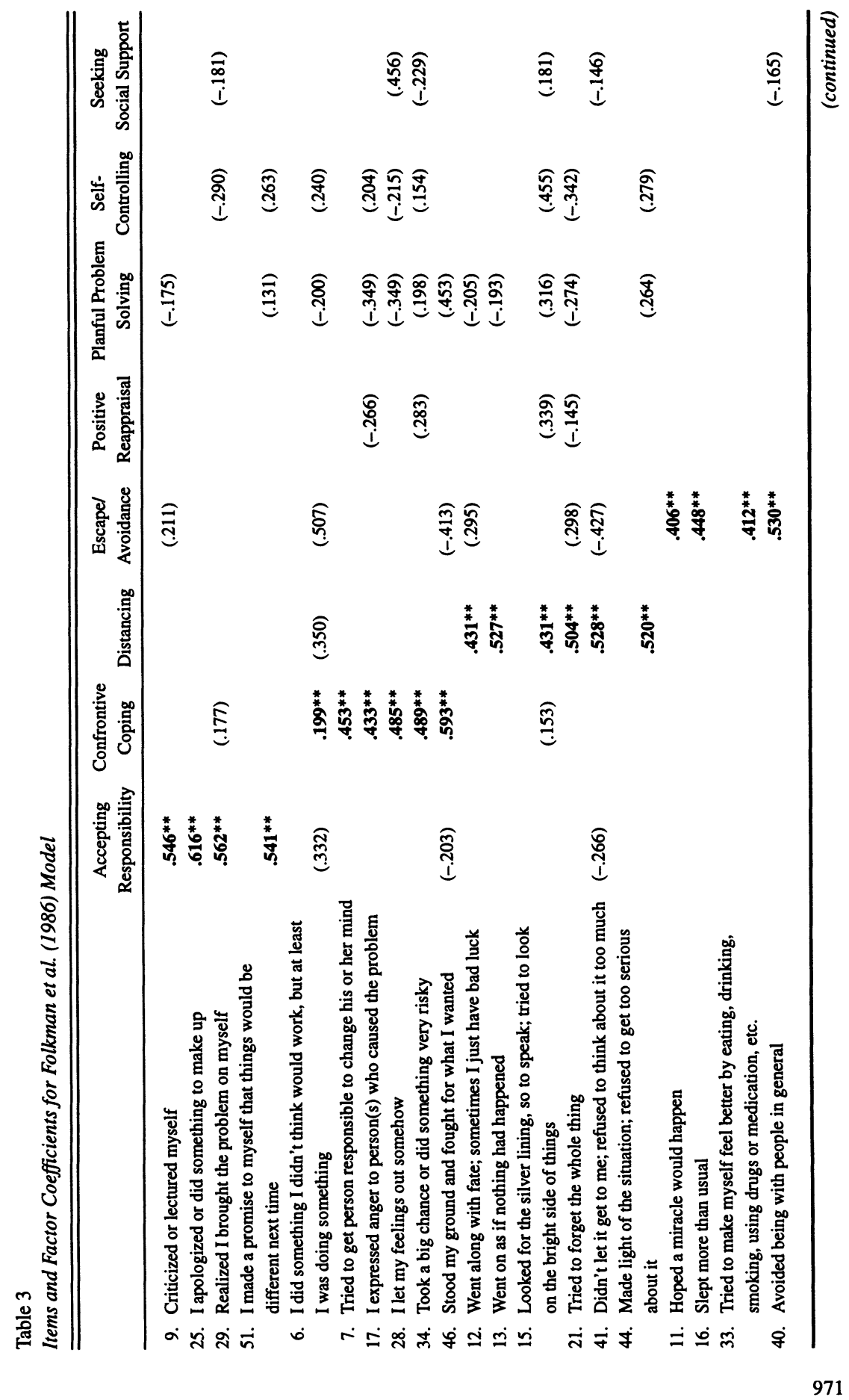




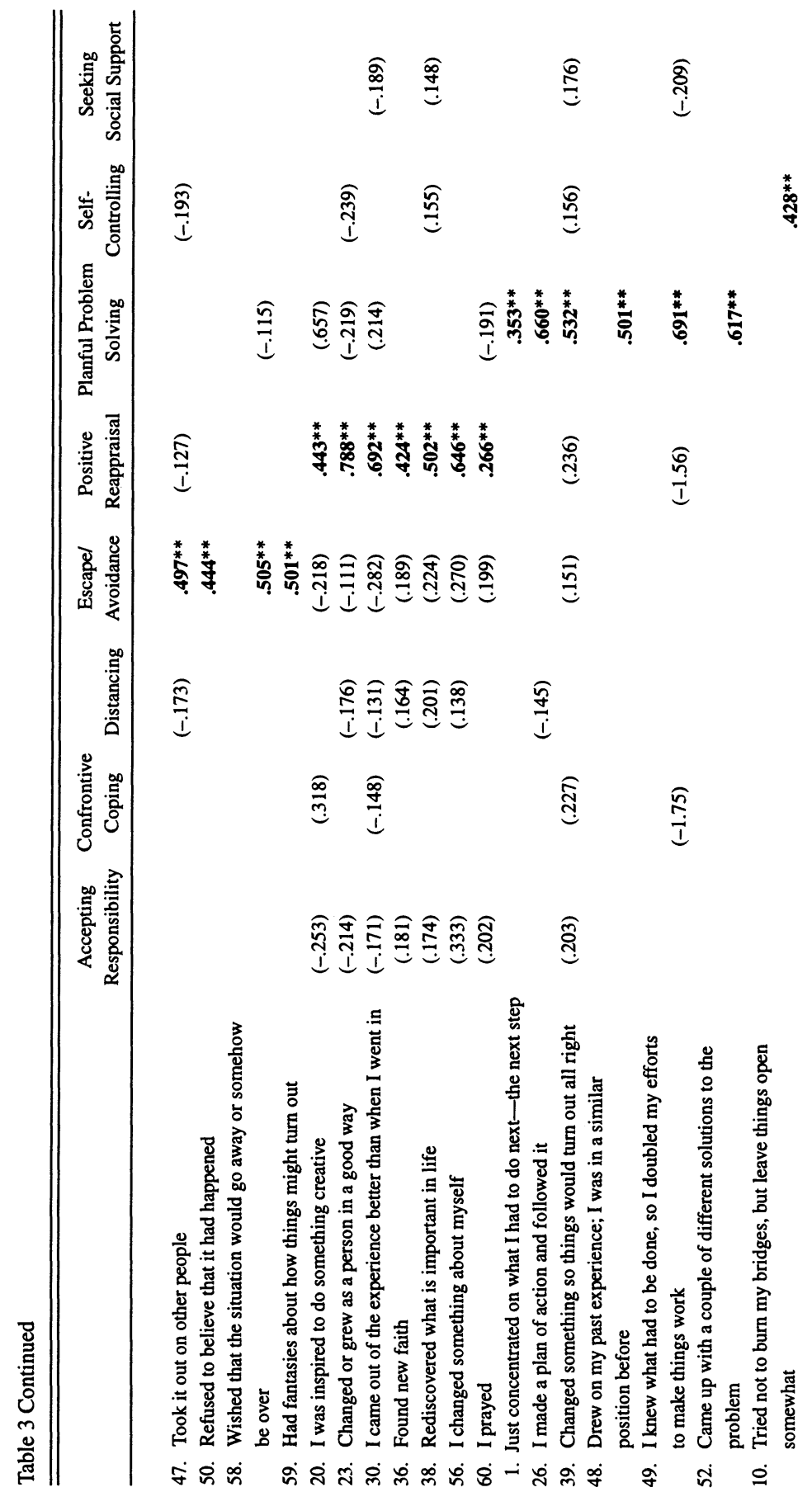




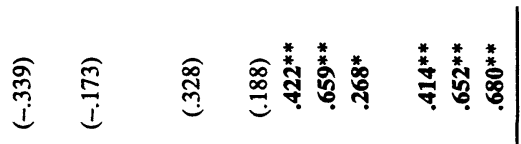

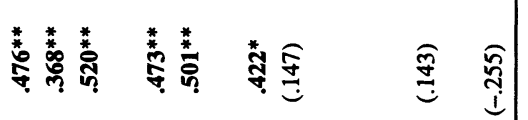

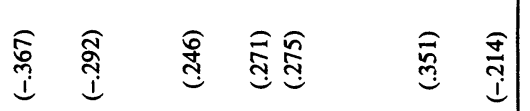

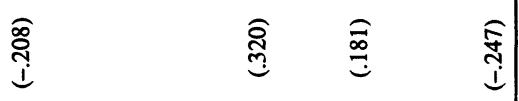

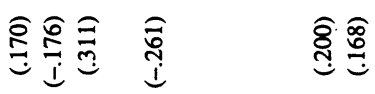

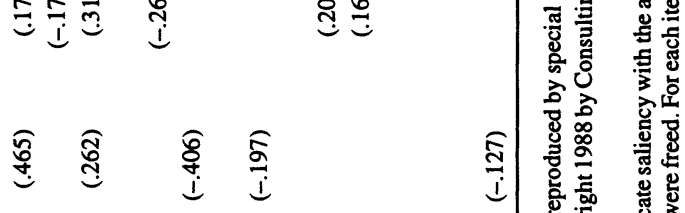

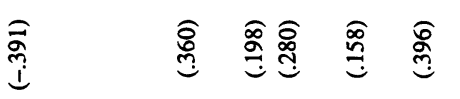

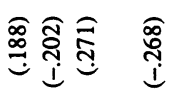

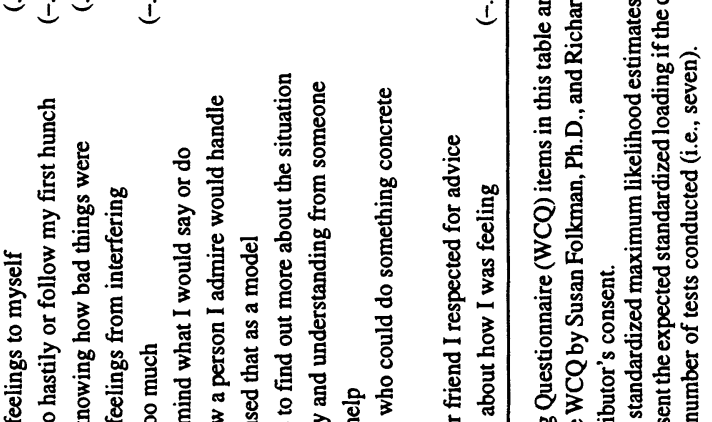

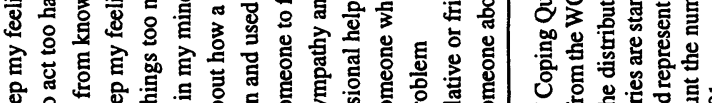

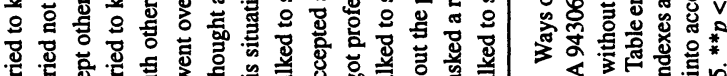

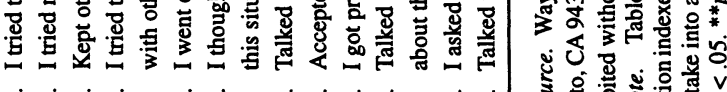

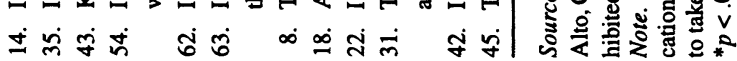




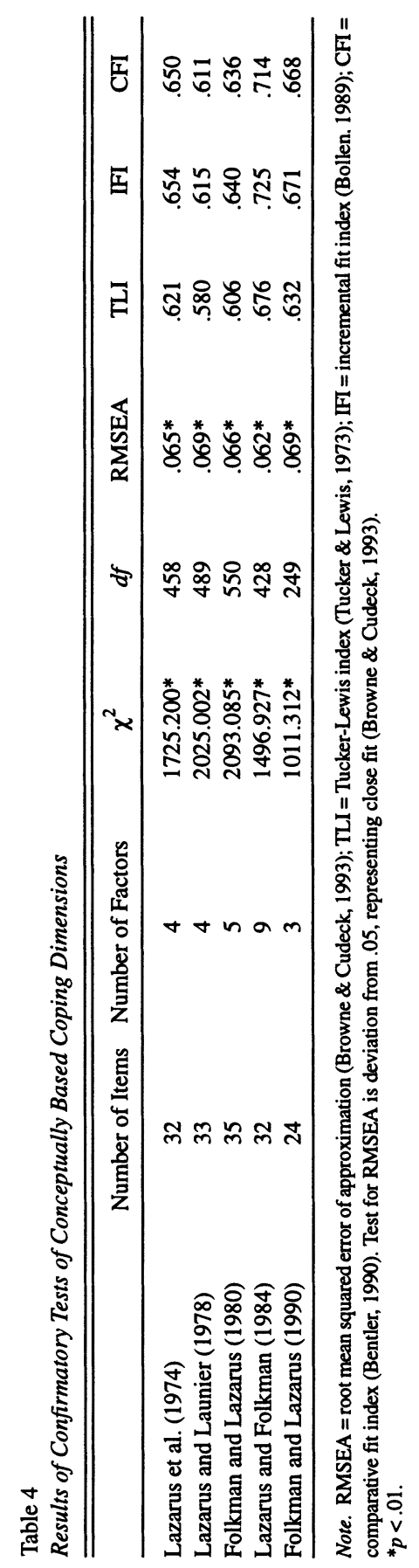


Across the five models, alphas averaged .57 and ranged from .28 to .76 . These values are somewhat lower than the corresponding values obtained for the confirmatory analyses of the exploratory factor models. Reliabilities were highest for subscale scores based on the Folkman and Lazarus (1990) model (due in part to the alpha of .73 for scores on the attention deployment scale), followed closely by the Folkman and Lazarus (1980) model. Overall, scores on 6 of the 25 scales yielded alpha values greater than or equal to .70 .

Standardized item coefficients averaged .41 across the five models, with the highest values for the Lazarus and Folkman (1984) model, averaging .47 and ranging from .06 to .70 , and the lowest values for the Folkman and Lazarus (1990) model, averaging .41 and ranging from .14 to .70. AVE values were low, averaging .22 and ranging from .15 to .37 , well below the .50 criterion. The highest AVE values were for the Lazarus and Folkman (1984) model, and the lowest were for the Lazarus and Launier (1978) model.

\section{Discussion}

The present study provides little support for the exploratory factor structures derived from the WCQ. Confirmatory factor analyses of these structures yielded poor fit, as evidenced by statistically significant chi-square and RMSEA statistics and TLI, IFI, and CFI values that averaged only $.65, .67$, and .67 , respectively, well below recommended standards. In addition, reliabilities of subscale scores based on these models were modest, with most failing to reach the .70 criterion suggested by Nunnally (1978) and none of the AVE values attaining the .50 threshold advocated by Fornell and Larcker (1981). Moreover, discriminant validity was not achieved in two models, as shown by factor correlations that did not significantly differ from unity. The best fit was obtained for a model using items that were assigned to conceptually similar factors in a majority of the exploratory analyses, but even this model demonstrated modest fit, lack of discriminant validity between two factors, and alphas that averaged only .59 across subscale scores, with five of eight alpha values failing to reach .70 .

Models based on Lazarus's conceptualization of coping fared somewhat worse than those derived from exploratory factor analyses, as indicated by higher RMSEA statistics and lower TLI, IFI, and CFI values, averaging .62, .66 , and .66, respectively. Reliabilities for subscale scores from these models also were modest, averaging approximately $15 \%$ lower than reliabilities for subscale scores based on the exploratory factor models and failing to reach .70 in most instances. Discriminant validity was poor, with four of five models yielding factor correlations that did not significantly differ from unity. The Lazarus and Folkman (1984) model yielded the best fit, although the fit of this model was modest in an absolute sense. Moreover, 6 of 36 factor correlations did not differ from unity, and alphas averaged .50, with none 
exceeding .62 . In addition, 11 of the 20 coping dimensions described by Lazarus and Folkman (1984) could not be included in the model due to insufficient items in the WCQ to represent factors for these dimensions.

Results for the Folkman and Lazarus (1985), Folkman et al. (1986), and Parker et al. (1993) models corroborate the findings of Parker et al. (1993) and Edwards and Baglioni (1993). In a confirmatory test of their own exploratory factor model, Parker et al. (1993) found GFI and AGFI values of .78 and .76, respectively, slightly lower than the values of .82 and .79 obtained in the present study. For the Folkman and Lazarus (1985) models, Parker et al. (1993) reported GFI and AGFI values of .81 and .79, respectively, for the six-factor model and .82 and .79, respectively, for the eight-factor model. GFI and AGFI values in the present study were slightly higher, reaching .82 and .80 , respectively, for the six-factor model and .83 and .81 , respectively, for the eight-factor model. For the Folkman et al. (1986) model, GFI and AGFI values were .78 and .76, respectively, in the Parker et al. (1993) study but were only .60 and .56, respectively, in the Edwards and Baglioni (1993) study. Values in the present study were .77 (GFI) and .75 (AGFI). Differences across these studies might be due partly to the influence of sample size on GFI and AGFI, which are biased downward in smaller samples (Gerbing \& Anderson, 1992). Sample sizes were largest for the present study, followed by the Parker et al. (1993) and Edwards and Baglioni (1993) studies, respectively, corresponding to the relative magnitudes of the GFI and AGFI values in these studies. Despite these differences, all three studies indicate that the Folkman and Lazarus (1985), Folkman et al. (1986), and Parker et al. (1993) models did not fit the data well. As noted previously, these findings are of particular concern for the Folkman et al. (1986) model, which currently is used to score the WCQ (Folkman \& Lazarus, 1988).

The preceding evidence provides little support for a range of factor models tested for the WCQ including those derived from exploratory factor analyses and those based on Lazarus's conceptualization of coping. The limited support for the exploratory factor models might be due partly to sampling variability, in that factor structures derived in one sample capitalize on idiosyncracies of the data and, hence, are likely to yield worse fit in other samples. Respondents also completed the WCQ in reference to stressful episodes that differed within and across studies, thereby introducing additional sources of variability across samples.

Other explanations for the poor performance of both the exploratory and conceptually-based models involve the inherent properties of the WCQ items. For example, several items are phrased in general terms and, thus, may represent multiple coping strategies (Parker et al., 1993). This is evidenced by Items 6 ("I did something I didn't think would work, but at least I was doing something"), 62 ("I went over in my mind what I would say or do"), and 63 ("I thought about how a person I admire would handle this situation and used that as a model"), which indicate that some coping strategy was used but 
do not describe the nature of the coping strategy itself. Items such as these are open to multiple interpretations and, therefore, may exhibit different patterns of correlations with other items across samples or reflect multiple factors within a given sample, as found in the present study.

Many WCQ items describe specific coping strategies that differ from those described by other items. For instance, Items 8 ("Talked to someone to find out more about the situation"), 18 ("Accepted sympathy and understanding from someone"), 22 ("I got professional help"), and 31 ("Talked to someone who could do something concrete about the problem") all are assigned to the seeking social support scale (Folkman \& Lazarus, 1988). However, these items represent conceptually distinct approaches to obtaining social support. Items that tap different facets of a construct increase unique item variance at the expense of common (i.e., true score) variance, thereby reducing reliability (Lord \& Novick, 1968). Such items may be viewed as formative indicators, meaning that they combine to define a construct (Blalock, 1971; Fornell $\&$ Bookstein, 1982). Formative indicators may be contrasted with reflective indicators, which are conceptually interchangeable manifestations of a construct. Reflective indicators are likely to covary because they share a common cause (i.e., the construct they represent), whereas formative indicators do not share a common cause and, hence, need not covary (Bollen \& Lennox, 1991). This reasoning is consistent with the correlations among WCQ Items $8,18,22$, and 31 , which averaged .19 and ranged from .05 to .36 in the present study. Treating formative indicators as representations of a single construct violates basic assumptions of classical test theory (Lord \& Novick, 1968) and yields measures that are conceptually ambiguous (Hattie, 1985).

Finally, based on descriptions of the development of the WCQ, it appears that individual WCQ items were not intended to map onto a particular set of a priori coping dimensions. According to Folkman and Lazarus (1980), the WCQ items describe

a broad range of behavioral and cognitive coping strategies ... derived from the framework suggested by Lazarus and colleagues (Lazarus, 1966; Lazarus \& Launier, 1978) and from suggestions offered in the coping literature (Mechanic, 1962; Sidle et al., 1969, Weisman \& Worden, 1976-1977). They include items from the domains of defensive coping (e.g., avoidance, intellectualization, isolation, suppression), information seeking, problem solving, palliation, inhibition of action, direct action, and magical thinking. (p. 224)

Although this description implies that the WCQ items represent these particular coping strategies, Folkman and Lazarus (1980) did not delineate the correspondence between these strategies and the WCQ items. Subsequent discussions of coping dimensions derived from Lazarus's theory (e.g., Folkman \& Lazarus, 1990; Lazarus \& Folkman, 1984) mentioned the WCQ but did not systematically link WCQ items to specific coping dimensions. The present study attempted to establish these links by assigning items to concep- 
tually based coping dimensions, but the resulting measurement models received little support. Thus, the WCQ apparently was developed not by following a domain sampling procedure, in which items are constructed to represent specific a priori constructs (Nunnally, 1978) but rather by assembling items that corresponded loosely to a variety of coping strategies. Measures developed in this manner provide little assurance that the resulting items will generate a meaningful factor structure or adequately represent a set of conceptually relevant dimensions.

\section{Limitations}

Although the present study has contributed to our understanding of the factorial stability and construct validity of WCQ scores, it has several limitations. First, the response rate (i.e., 36\%) suggests the operation of selfselection bias. However, demographic information was not available for all potential respondents, making it impossible to determine how respondents differed from nonrespondents. Second, we used a single sample to test all models, thereby controlling for sampling variability. However, our results may not generalize beyond the data used. This concern is assuaged somewhat by the consistency between the findings of the present study and those reported elsewhere (e.g., Parker et al., 1993). Nonetheless, the generalizability of our findings should be evaluated using other samples. Third, by using alpha to estimate reliability, we implicitly assumed that the WCQ items were tau equivalent, meaning that they have equal true score variances. When this assumption is violated, alpha underestimates reliability (Smith, 1974). Methods that do not require tau equivalence (Jöreskog, 1971; Smith, 1974) produced reliability estimates that averaged approximately .01 higher across all models analyzed, indicating that the downward bias associated with alpha was minimal in the present study. Finally, we used maximum likelihood estimation for data that were not multivariate normal, which might have inflated standard errors and chi-square values. This problem may be addressed in future studies by obtaining samples large enough to use estimation methods that do not require multivariate normality (Browne, 1984) and by increasing the number of response categories for the WCQ items.

\section{Implications for the Use of the Ways of Coping Questionnaire}

Despite the limitations of the present study, our findings have several implications for the use and further development of the WCQ. First, the current scoring procedure for the WCQ (Folkman \& Lazarus, 1988) cannot be recommended (Edwards \& Baglioni, 1993; Parker et al., 1993). Although scores on the positive reappraisal and planful problem-solving subscales yielded reliabilities greater than .70 , reliabilities for the remaining subscales were 
marginal to poor, and the fit of the model to the data was inadequate. Other possible scoring procedures for the WCQ, including those derived from previous exploratory factor analyses and the conceptually based approach used in the present study, also did not receive strong support. Therefore, it appears that a valid scoring procedure for the WCQ currently is not available.

Although there is little evidence to support the use of the WCQ in its current form, certain subscales extracted from the WCQ may exhibit adequate psychometric properties. For example, Items $11,55,57,58$, and 59 were related to a wishful thinking factor in a majority of the exploratory factor analyses, and scores on these items yielded an alpha of .75 in the present study. Although Item 57 ("I daydreamed or imagined a better time or place than the one I was in") implied avoidance, the remaining items share a reasonably consistent conceptual focus on wishing the situation would resolve itself. Likewise, Items 8, 18, 22, 31, 42, and 45 were consistently related to a seeking social support factor, and data from this study produced an alpha of .72 . However, as noted previously, these items represent distinct facets of social support, obfuscating the interpretation of a scale based on these items. Scores on certain other scales yielded adequate reliability and discriminant validity but represented factors that did not emerge consistently across samples and, hence, might reflect unstable coping dimensions.

Finally, further development of the WCQ should draw from specific coping dimensions derived from Lazarus's theory. As noted earlier, this theory has many conceptual strengths and has profoundly influenced stress and coping research. However, due to variations in the dimensionalization of coping and weak linkages between these dimensions and the WCQ, the coping processes specified by the theory are difficult to examine empirically using the WCQ. This problem may be overcome by identifying coping dimensions central to the theory, developing operational definitions of these dimensions, and constructing items that reflect these dimensions using a domain sampling procedure (Nunnally, 1978). The resulting factor structure may then be tested and refined using confirmatory procedures, with the goal of generating scales whose scores achieve adequate reliability and construct validity. These scales will enable coping researchers to investigate the full range of predictions offered by Lazarus's theory.

\section{APPENDIX \\ Operational Definitions of Coping Dimensions}

Information seeking: Gathering information that might be used to change the transaction or make it seem more under control (Folkman \& Lazarus, 1980, p. 224; Lazarus \& Launier, 1978, p. 316).

Direct action: Taking action to directly manage or alter the situation or oneself (Folkman \& Lazarus, 1980, p. 224; Lazarus \& Launier, 1978, p. 316). 
Inhibition of action: Withholding action that could potentially make things worse (Folkman \& Lazarus, 1980, p. 224; Lazarus \& Launier, 1978, p. 317).

Intrapsychic coping: Cognitive processes intended to regulate emotional distress (Lazarus \& Launier, 1978, p. 317).

Deployment of attention: Directing attention toward or away from the source of distress (Folkman \& Lazarus, 1990, p. 319).

Changing the subjective meaning or significance of the transaction: Cognitive coping activities intended to alter the subjective meaning or significance of the transaction (Folkman \& Lazarus, 1990, p. 321).

Changing the actual terms of the transaction: Cognitive problem solving or direct action on the environment or oneself (Folkman \& Lazarus, 1990, p. 323).

Planful problem solving: Using rational problem-solving techniques (Folkman \& Lazarus, 1990, p. 320; Lazarus \& Folkman, 1984, p. 152).

Defining the problem: Determining the meaning and significance of the problem (Lazarus \& Folkman, 1984, p. 152).

Generating potential solutions: Coming up with one or more alternative solutions to the problem (Lazarus \& Folkman, 1984, p. 152).

Evaluating potential solutions: Weighing alternative solutions in terms of their costs and benefits (Lazarus \& Folkman, 1984, p. 152).

Implementing potential solutions: Choosing and acting on a potential solution to the problem (Lazarus \& Folkman, 1984, p. 152).

Shifting one's aspiration level: Moving one's goals or aspirations to be more in line with the current situation (Lazarus \& Folkman, 1984, p. 152).

Reducing ego involvement: Attempting to reduce the overall significance of the situation to oneself (Lazarus \& Folkman, 1984, p. 152).

Finding alternative channels of gratification: Looking for other ways in which to seek pleasure (Lazarus \& Folkman, 1984, p. 152).

Avoidance: Trying not to think about the problem (Lazarus, 1993, p. 238; Lazarus \& Folkman, 1984, p. 150).

Minimization: Deciding that the problem is not as severe or important as once believed (Lazarus \& Folkman, 1984, p. 150).

Distancing: Dissociating or detaching oneself psychologically or physically from the problem (Folkman \& Lazarus, 1990, p. 321; Lazarus \& Folkman, 1984, pp. 150, 238).

Selective attention: Directing attention away from troubling aspects of the transaction or toward its positive aspects (Lazarus \& Folkman, 1984, p. 150).

Positive comparisons: Thinking of other experiences that are worse than the current problem (Lazarus \& Folkman, 1984, p. 150).

Seeking positive value from negative events: Thinking of ways in which the problem may actually result in some benefit (Lazarus \& Folkman, 1984, p. 150).

Palliation: Attempting to lessen emotional distress without actually solving the problem (Folkman \& Lazarus, 1980, p. 224).

Self-blame: Blaming oneself or taking personal responsibility for the problem (Lazarus \& Folkman, 1984, p. 150).

Exercise: Engaging in physical exercise (Lazarus \& Folkman, 1984, p. 151).

Meditation: Engaging in deep, continued thought (Lazarus \& Folkman, 1984, p. 151).

Alcohol use: Drinking alcohol (Lazarus \& Folkman, 1984, p. 151).

Venting anger: Outwardly expressing anger or irritation (Lazarus \& Folkman, 1984, p. 151).

Seeking emotional support: Seeking advice, information, sympathy, or assistance from another person (Lazarus \& Folkman, 1984, p. 151). 
Intellectualization: Taking a detached, intellectual perspective without emotional involvement (Lazarus, 1966, p. 47).

Magical thinking: Engaging in magical or superstitious thoughts or behaviors (Folkman \& Lazarus, 1980, p. 224; Mechanic, 1962, p. 136).

Note. References and page numbers were omitted when the definitions were presented to the judges.

\section{References}

Aldwin, C., Folkman, S., Schaefer, C., Coyne, J. C., \& Lazarus, R. S. (1980, August). Ways of coping: A process measure. Paper presented at the annual meeting of the American Psychological Association, Montreal.

Aldwin, C. M., \& Revenson, T. A. (1987). Does coping help? A reexamination of the relation between coping and mental health. Journal of Personality and Social Psychology, 53, 337-348.

Atkinson, M., \& Violato, C. (1993). A factor analysis of the Ways of Coping Questionnaire based on data from saddening experiences. Psychological Reports, 72, 1159-1164.

Bentler, P. M. (1990). Comparative fit indexes in structural models. Psychological Bulletin, 107, 238-246.

Bentler, P. M., \& Bonett, D. G. (1980). Significance tests and goodness of fit in the analysis of covariance structures. Psychological Bulletin, 88, 588-606.

Bentler, P. M., \& Chou, C. (1987). Practical issues in structural modelling. Sociological Methods \& Research, 16, 78-117.

Blalock, H. M. (1971). Causal models involving unobserved variables in stimulus-response situations. In H. M. Blalock (Ed.), Causal models in the social sciences (pp. 335-347). Chicago: Aldine.

Bollen, K. A. (1989a). A new incremental fit index for general structural equation models. Sociological Methods \& Research, 17, 303-316.

Bollen, K. A. (1989b). Structural equations with latent variables. New York: John Wiley.

Bollen, K., \& Lennox, R. (1991). Conventional wisdom on measurement: A structural equation perspective. Psychological Bulletin, 110, 305-314.

Bollen, K. A., \& Long, J. S. (1993). Testing structural equation models. Newbury Park, CA: Sage.

Browne, M. W. (1984). Asymptotic distribution free methods in analysis of covariance structures. British Journal of Mathematical and Statistical Psychology, 37, 62-83.

Browne, M. W., \& Cudeck, R. (1993). Alternative ways of assessing model fit. In K. A. Bollen \& J. S. Long (Eds.), Testing structural equation models (pp. 136-162). Newbury Park, CA: Sage.

Campbell, J. P. (1976). Psychometric theory. In M. Dunnette (Ed.), Handbook of industrial and organizational psychology (pp. 185-222). Chicago: Rand McNally.

Carver, C. S., \& Scheier, M. F. (1994). Situational coping and coping dispositions in a stressful transaction. Journal of Personality and Social Psychology, 66, 184-195.

Cohen, F. (1987). Measurement of coping. In S. V. Kasl \& C. L. Cooper (Eds.), Stress and health: Issues in research methodology (pp. 283-305). Chichester, UK: Wiley.

Cohen, F., \& Lazarus, R. S. (1973). Active coping processes, coping dispositions, and recovery from surgery. Psychosomatic Medicine, 35, 375-389.

Coyne, J. C., \& Downey, G. (1991). Social factors and psychopathology: Stress, social support, and coping processes. Annual Review of Psychology, 42, 401-425.

Cronbach, L. J. (1951). Coefficient alpha and the internal structure of tests. Psychometrika, 16, 297-334.

Dewe, P., Cox, T., \& Ferguson, E. (1993). Individual strategies for coping with stress at work: A review. Work \& Stress, 7, 5-15. 
Edwards, J. R. (1988). The determinants and consequences of coping with stress. In C. L. Cooper \& R. Payne (Eds.), Causes, coping, and consequences of stress at work (pp. 233-263). New York: John Wiley.

Edwards, J. R., \& Baglioni, A. J., Jr. (1993). The measurement of coping with stress: Construct validity of the Ways of Coping Checklist and the Cybernetic Coping Scale. Work \& Stress, 7, 17-31.

Endler, N. S., \& Parker, J.D.A. (1990). Multidimensional assessment of coping: A critical evaluation. Journal of Personality and Social Psychology, 58, 844-854.

Folkman, S. (1982). An approach to the measurement of coping. Journal of Occupational Behavior, 3, 95-108.

Folkman, S., \& Lazarus, R. S. (1980). An analysis of coping in a middle-aged community sample. Journal of Health and Social Behavior, 21, 219-239.

Folkman, S., \& Lazarus, R. S. (1985). If it changes, it must be a process: A study of emotion and coping during three stages of a college examination. Journal of Personality and Social Psychology, 48, 150-170.

Folkman, S., \& Lazarus, R. S. (1988). Manual for the Ways of Coping Questionnaire. Palo Alto, CA: Consulting Psychologists Press.

Folkman, S., \& Lazarus, R. S. (1990). Coping and emotion. In N. Stein, B. Leventhal, \& T. Trabasso (Eds.), Psychological and biological approaches to emotion (pp. 313-332). Hillsdale, NJ: Lawrence Erlbaum.

Folkman, S., Lazarus, R. S., Dunkel-Schetter, C., DeLongis, A., \& Gruen, R. J. (1986). Dynamics of a stressful encounter: Cognitive appraisal, coping, and encounter outcomes. Journal of Personality and Social Psychology, 50, 992-1003.

Fornell, C., \& Bookstein, F. L. (1982). Two structural equation models: LISREL and PLS applied to consumer exit-voice theory. Journal of Marketing Research, 19, 440-452.

Fornell, C., \& Larcker, D. F. (1981). Evaluating structural equation models with unobservable variables and measurement error. Journal of Marketing Research, 18, 39-50.

Gerbing, D. W., \& Anderson, J. C. (1992). Monte Carlo evaluations of goodness of fit indices for structural equation models. Sociological Methods \& Research, 21, 132-160.

Haan, N. A. (1977). Coping and defending: Processes of self-environment organization. New York: Academic Press.

Hattie, J. (1985). Methodology review: Assessing unidimensionality of tests and items. Applied Psychological Measurement, 9, 139-164.

Jöreskog, K. G. (1971). Statistical analysis of sets of congeneric tests. Psychometrika, 36, 109-133.

Jöreskog, K. G., \& Sörbom, D. (1993). LISREL 8: Structural equation modeling with the SIMPLIS command language. Hillsdale, $\mathrm{NJ}$ : Lawrence Erlbaum.

Kobasa, S. C. (1979). Personality and resistance to illness. American Journal of Community Psychology, 7, 413-423.

Latack, J. C., \& Havlovic, S. J. (1992). Coping with job stress: A conceptual evaluation framework for coping measures. Journal of Organizational Behavior, 13, 479-508.

Lazarus, R. S. (1966). Psychological stress and the coping process. New York: McGraw-Hill.

Lazarus, R. S. (1993). Coping theory and research: Past, present, and future. Psychosomatic Medicine, 55, 234-247.

Lazarus, R. S., Averill, J. R., \& Opton, E. M., Jr. (1974). The psychology of coping: Issues of research and assessment. In G. V. Coelho, D. A. Hamburg, \& J. E. Adams (Eds.), Coping and adaptation (pp. 249-315). New York: Basic Books.

Lazarus, R. S., \& Folkman, S. (1984). Stress, coping, and adaptation. New York: Springer.

Lazarus, R. S., \& Launier, R. (1978). Stress-related transactions between person and environment. In L. A. Pervin \& M. Lewis (Eds.), Perspectives in interactional psychology (pp. 287327). New York: Plenum. 
Lefcourt, H. M., \& Davidson-Katz, K. (1991). Locus of control and health. In C. R. Snyder \& D. R. Forsyth (Eds.), Handbook of social and clinical psychology: The health perspective (pp. 246-266). New York: Pergamon.

Long, J. S. (1983). Confirmatory factor analysis: A preface to LISREL. Beverly Hills, CA: Sage.

Lord, F. M., \& Novick, M. R. (1968). Statistical theories of mental test scores. Reading, MA: Addison-Wesley.

Marsh, H. W., Balla, J. R., \& McDonald, R. P. (1988). Goodness-of-fit indexes in confirmatory factor analysis: The effect of sample size. Psychological Bulletin, 103, 391-410.

McDonald, R. P., \& Marsh, H. W. (1990). Choosing a multivariate model: Noncentrality and goodness of fit. Psychological Bulletin, 107, 247-255.

Mechanic, D. (1962). Students under stress. New York: Free Press.

Mishel, M. H., \& Sorenson, D. S. (1993). Revision of the Ways of Coping Checklist for a clinical population. Western Journal of Nursing Research, 15, 59-76.

Monat, A., \& Lazarus, R. S. (Eds.). (1991). Stress and coping: An anthology (3rd ed.). New York: Columbia University Press.

Nunnally, J. C. (1978). Psychometric theory (2nd ed.). New York: McGraw-Hill.

Parker, J.D.A., Endler, N. S., \& Bagby, R. M. (1993). If it changes, it might be unstable: Examining the factor structure of the Ways of Coping Questionnaire. Psychological Assessment, 5 , 361-368.

Parkes, K. R. (1984). Locus of control, cognitive appraisal, and coping in stressful episodes. Journal of Personality and Social Psychology, 46, 655-668.

Rychlak, J. F. (1981). Introduction to personality and psychotherapy: A theory-construction approach (2nd ed.). Boston: Houghton Mifflin.

Satorra, A. (1990). Robustness issues in structural equation modeling: A review of recent developments. Quality and Quantity, 24, 367-386.

Shrout, P. E., \& Fleiss, J. L. (1979). Intraclass correlations: Uses in assessing rater reliability. Psychological Bulletin, 86, 420-428.

Sidle, A., Moos, R. H., Adams, J., \& Cady, P. (1969). Development of a coping scale. Archives of General Psychiatry, 20, 225-232.

Smith, K. W. (1974). On estimating the reliability of composite indexes through factor analysis. Sociological Methods \& Research, 2, 485-510.

Smyth, K. A., \& Williams, P. D. (1991). Patterns of coping in Black working women. Behavioral Medicine, 17, 40-46.

Steiger, J. H. (1990). Structural model evaluation and modification: An interval estimation approach. Multivariate Behavioral Research, 25, 173-180.

Tennen, H., \& Herzberger, S. (1985). Ways of Coping Scale. In D. J. Keyser \& R. C. Sweetland (Eds.), Test critiques (Vol. 3, pp. 686-697). Kansas City, KS: Test Corporation of America.

Tucker, L. R., \& Lewis, C. (1973). The reliability coefficient for maximum likelihood factor analysis. Psychometrika, 38, 1-10.

Valliant, G. E. (1977). Adaptation to life. Boston: Little, Brown.

Vingerhoets, A. J., \& Flohr, P. J. (1984). Type A behaviour and self-reports of coping preferences. British Journal of Medical Psychology, 57, 15-21.

Vitaliano, P. P., Russo, J., Carr, J. E., Maiuro, R. D., \& Becker, J. (1985). The Ways of Coping Checklist: Revision and psychometric properties. Multivariate Behavioral Research, 20, 3-26.

Weisman, A. D., \& Worden, J. W. (1976-1977). The existential plight of cancer: Significance of the first 100 days. International Journal of Psychiatry in Medicine, 7, 1-15. 